\title{
Two Genetic Clusters in Swine Hemoplasmas Revealed by Analyses of the 16S rRNA and RNase P RNA Genes
}

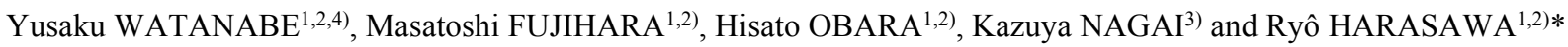 \\ ${ }^{1)}$ Department of Veterinary Microbiology, Faculty of Agriculture, Iwate University, Morioka 020-8550, ${ }^{2}$ Department of Applied \\ Veterinary Science, The United Graduate School of Veterinary Sciences, Gifu University, Gifu 501-1193, ${ }^{3)}$ Cryobiofrontier Research \\ Center, Faculty of Agriculture, Iwate University, Morioka 020-8550 and ${ }^{4}$ Bremen Vet Center, Yahaba 028-3602, Japan
}

(Received 16 June 2011/Accepted 15 July 2011/Published online in J-STAGE 29 July 2011)

\begin{abstract}
Only two hemoplasma species, Eperythrozoon parvum and Mycoplasma suis, have been recognized in pigs. Here we demonstrate the genetic variations among six hemoplasma strains detected from pigs, by analyzing the 16S rRNA and RNase P RNA (rnpB) genes, and propose a novel hemoplasma taxon that has not been described previously. Phylogenetic trees based on the nucleotide sequence of the 16S rRNA gene indicated that these six hemoplasmas were divided into two clusters representing $M$. suis and a novel taxon. We further examined the primary and secondary structures of the nucleotide sequences of the rnpB gene of the novel taxon, and found it distinct from that of $M$. suis. In conclusion, we unveiled a genetic cluster distinct from $M$. suis, suggesting a new swine hemoplasma species or E. parvum. Our findings also suggest that this novel cluster should be included in the genus Mycoplasma. KEY WORDS: Eperythrozoon, hemoplasma, mycoplasma.
\end{abstract}

J. Vet. Med. Sci. 73(12): 1657-1661, 2011

Hemoplasma is a trivial name for the group of hemotrophic prokaryotes that lack a cell wall, but have never been cultured in vitro [10]. This group is composed of former Eperythrozoon and Hemobartonella species as well as newly identified hemotrophic mycoplasmas. Currently only two hemoplasma species, Eperythrozoon parvum and Mycoplasma suis previously known as E. suis, are recognized in pigs (Sus scrofa domestica) [11, 12, 18]. Hemoplasmas parasitize the cell surface of swine erythrocyes, where it causes membrane deformation and damage [10, 25]. Damaged erythrocytes are subsequently removed from the blood circulation, resulting in hemolytic anemia and icterus in pig [10].

The clinical signs of $M$. suis infection are variable, but in the acute form, sows usually develop anemia, icterus and anorexia for a few days [6], and it causes severe anemia in newborn and weaned piglets [5]. Chronic carrier states have been associated with reproductive failures in sows and decreased weight gains in piglet [26]. Mycoplasmas have host specificity to some extent, but human infections with M. suis have been reported in China, suggesting a zoonotic pathogen $[23,24]$. Pathogenicity of E. parvum has not well been documented, but it also causes severe anaemia accompanied with fever on splenectomised pig [1].

In the present study, we examined the genetic variations among swine hemoplasmas detected from a commercial farm in Japan. Heparin-anticoagulated blood samples collected from 12 pigs in Morioka (latitude 39.7N and longitude 141.1E), Japan in December 2010, were stored at $-80^{\circ} \mathrm{C}$ prior to analysis. Total DNA was extracted from 200 $\mu l$ of the Heparin-anticoagulated whole blood samples by

\footnotetext{
* Correspondence to: Harasawa, R., Department of Veterinary Microbiology, Faculty of Agriculture, Iwate University, Morioka 020-8550, Japan.

e-mail: harasawa-tky@umin.ac.jp
}

using the QIAamp DNA Blood Mini Kit (QIAGEN, Hilden, Germany) according to the manufacturer's instructions, eluting into $200 \mu l$ of buffer $\mathrm{AE}$, and stored at $-20^{\circ} \mathrm{C}$ until examination in the PCR assay.

For the preliminary screening of hemoplasma infections by real-time PCR, specific PCR primers (forward primer: 5'-ATATTCCTACGGGAAGCAGC-3' and reverse primer: 5'-ACCGCAGCTGCTGGCACATA-3') for the 16S rRNA gene of hemoplasmas were used as described previously [22]. After real-time PCR, melting experiment was performed as described previously [4]. Six (50\%) out of the 12 blood samples tested by real-time PCR were found to be positive for hemplasma infection. No mixed infection with both the hemoplasma species was found in this screening test. The six samples designated Morioka1, Morioka4, Morioka5, Morioka6, Morioka8, and Morioka9 were divided into two clusters, $\mathrm{A}$ and $\mathrm{B}$, according to the melting temperature $(T m)$ levels. $T m$ (mean $\pm \mathrm{SE}$ ) of the cluster A consisting of Morioka5, Morioka6, Morioka8 showed lower temperature at $82.40 \pm 0.08^{\circ} \mathrm{C}$, and the cluster B including Morioka1, Morioka4 and Morioka9 showed higher temperature at $83.33 \pm 0.22^{\circ} \mathrm{C}$.

These six positive samples were further subjected to endpoint PCR to amplify entire region of the $16 \mathrm{~S}$ rRNA gene by using universal primers as described previously [22]. DNA extracted from PCR products was subjected to direct sequencing in a 3500 Genetic Analyzer (Applied Biosystems, Foster City, CA, U.S.A.). Six nucleotide sequences of the almost entire region of the 16S rRNA gene have been deposited to the DDBJ, EMBL, GSDB and NCBI nucleotide sequence databases under the accession numbers AB610845 to AB610850.

A phylogenetic tree constructed with the neighbor-joining method [16] from a distance matrix corrected for nucleotide substitutions by the Kimura two-parameter model [7] 
divided the six swine hemoplasmas into two clusters, A and $\mathrm{B}$, as same as the $T m$ values in the real-time PCR experiments (Fig. 1). Nucleotide sequences of Morioka5, Morioka6 and Morioka8 in cluster A were identical and closely related to M. suis (more than $99 \%$ homology) in the phylogenetic tree of the 16S rRNA gene sequences. On the contrary, the three strains, Morioka1, Morioka4 and Morioka9, in cluster B were distinct from the former sequences (less than $95 \%$ homology), suggesting a different taxon in the hemoplasma taxonomy according to the cutoff value of the $16 \mathrm{~S}$ rRNA gene sequence identity for species definition [2].

We have further examined the nucleotide sequences of the RNase P RNA ( $r n p B$ ) gene of the cluster B hemoplasmas, a distinct taxon revealed by $16 \mathrm{~S}$ rRNA sequences, to compare with other hemoplasma species [14]. The rnpB gene has been shown to be suitable for phylogenetic discrimination of closely related taxonomic groups when examined by the $16 \mathrm{~S}$ rRNA sequence comparison [20]. The $r n p B$ gene of only the strains Morika1, Morika4, and Morioka9 in cluster B was successfully amplified by endpint PCR with forward primer [5'-TATTTAAAGTAGAGGAAAGTC-3' equivalent to nucleotide numbers 10 to 30 of M. suis (EF523602)] and reverse primer [5'-GAGGAGTTTACCGCGTTT-3' equivalent to nucleotide numbers 206 to 223 of M. suis (EF523602)]. Reaction was the same as used for the amplification of the 16S rRNA gene except for the annealing temperature at $56^{\circ} \mathrm{C}$ instead of $58^{\circ} \mathrm{C}$. PCR product was then subjected to direct sequencing as described previously and the nucleotide sequences of the $r n p B$ gene of these strains, which were identical, have been deposited to the DNA database under the accession numbers AB641639 to AB641641. A phylogenetic tree was constructed with the $r n p B$ gene sequences of these three strains with other hemoplasma sequences from DNA databases (Fig. 2). The rnpB gene sequence of the three strains in cluster B showed less than $90 \%$ homology to M. suis, and it included deletion of three serial nucleotides in the gene, supporting the notion

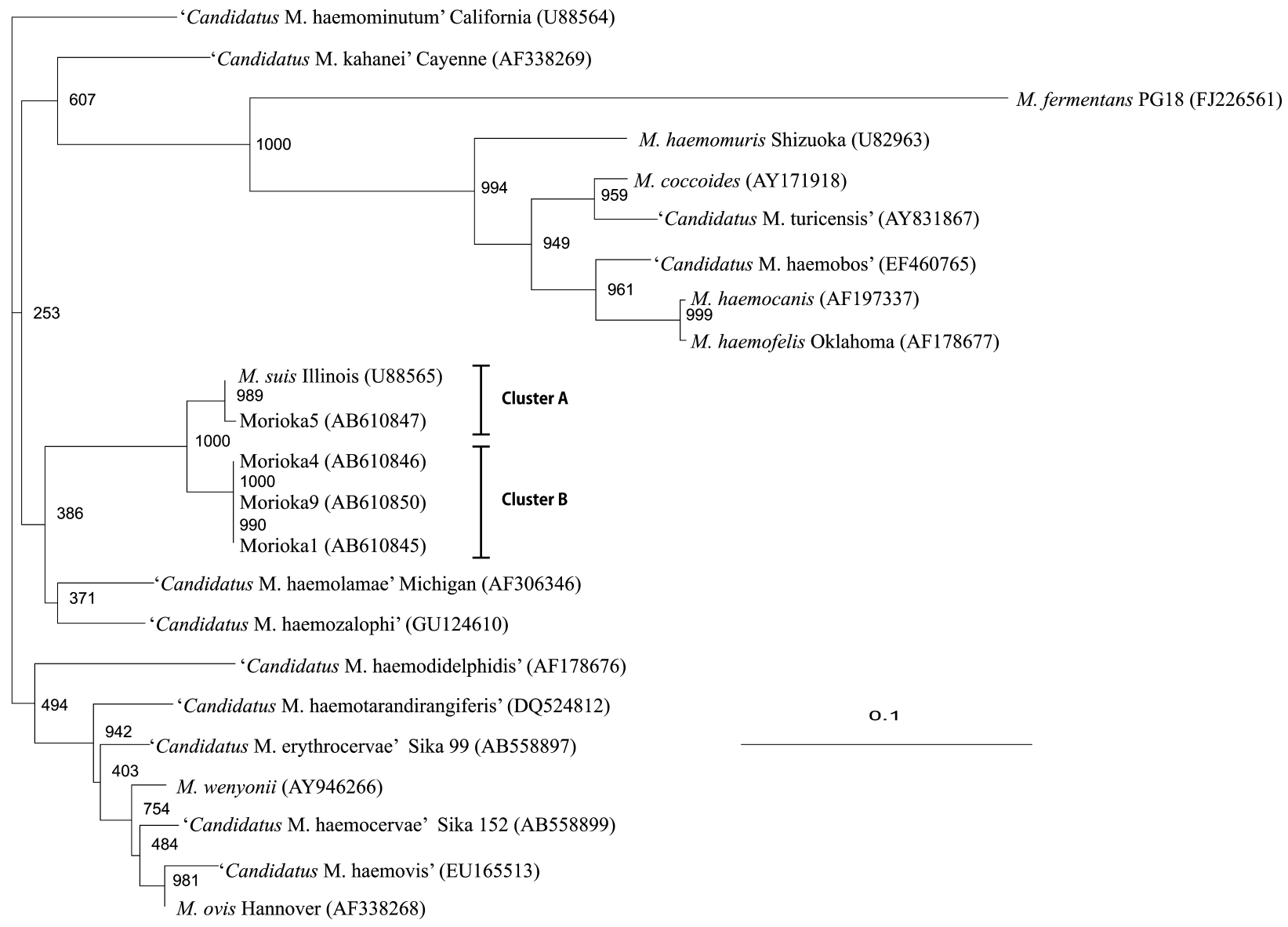

Fig. 1. A phylogenetic tree based on the 16S rRNA gene comparison among mycoplasmas including 18 hemoplasma species (accession numbers are given in a parenthesis) and putative taxa created by clusters A and B. Genetic distances were compared with CLUTAL W [21]. Morioka5, representative of morioka6 and Morioka8 in cluster A was identified as M. suis. Morioka4, Morioka9 and Morioka1 in cluster B were distinct from M. suis. Numbers in the relevant branches refer to the values of boot-strap probability of 1,000 replications. Scale bar indicates the estimated evolutionary distance. 


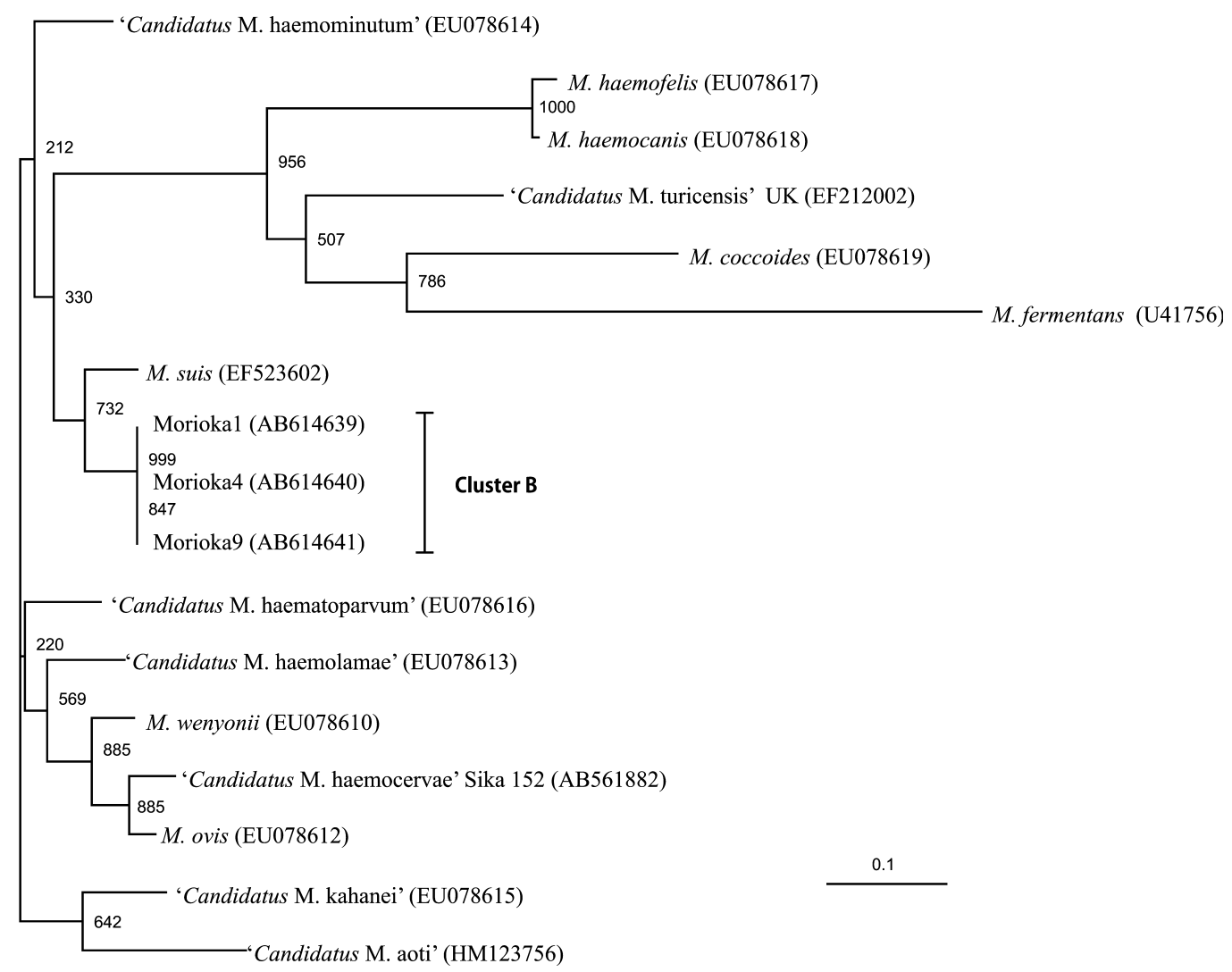

Fig. 2. A phylogenetic tree generated by partial $r n p B$ gene sequences among mycoplasmas including 13 hemoplasma species (accession numbers are given in a parenthesis) and a putative taxon as cluster B. Genetic distances were compared with CLUTAL W [21]. Hemoplasma strains Morioka1, Morioka4 and Morioka9 in cluster B were detected from a commercial swine farm in the Iwate prefecture. Numbers in the relevant branches refer to the values of bootstrap probability of 1,000 replications. Scale bar indicates the estimated evolutionary distance.

$\begin{array}{cc}\text { A A } & \text { A A } \\ \text { G A } & \text { G A } \\ \text { A-T } & \text { A-T } \\ \text { A-T } & \text { G - C } \\ \text { A-T } & \text { A - T } \\ \text { T- A } & \text { T - A } \\ \text { C- G } & \text { C - G } \\ \text { A - T } & \text { G - T } \\ \text { A - T } & \text { G - T } \\ \text { - C - G- 3' } & \text { 5'- C - G - 3' } \\ \text { (-7.20) } & \text { (-6.50) } \\ \text { Morioka1 } & \text { M. suis }\end{array}$

Fig. 3. Comparison of the representative secondary structures containing the GAAA tetraloop modules in the $\operatorname{rnpB}$ gene. $M$. suis sequences in the left and right structures correspond to the nucleotide numbers $93-112$ and 189-206, respectively, of the accession number EF523602. Homologous sequences between M. suis and Moriokal are shown on a gray background. Minimum free energy $(\mathrm{Kcal} / \mathrm{mol})$ is given in a parenthesis. that the cluster B was distinct from M. suis.

As an additional means of assessing genetic relatedness between $M$. suis and cluster B, we compared the secondary structures of $r n p B$ predicted according to the algorithm of Zuker and Stiegler [27]. Two copies of the GAAA tetraloop module were allocated in the $\operatorname{rnp} B$ gene in the cluster B as well as $M$. suis. Transitional substitutions between pyrimidines and purines were evident in the stem regions of the GAAA tetraloop modules (Fig. 3).

The GAAA tetraloop has high affinity for the motif called tetraloop receptor and exerts an important function in ribozyme activity [8,9]. Nucleotide base-pairings at the stem region were variable between these two hemoplasma taxa, but were capable to form a stable secondary structure to minimize free energy. The folding energy of the each GAAA tetraloop module showed substantial negative free energy [3]. Palindromic nucleotide substitutions in basepairings correspond to radical evolutionary changes, which can generate new genotypes or species. Several secondary structure modules in $r n p B$ molecules have been predicted from the phylogenetic comparison, which play the interac- 
tion with a defined structural motif. Analysis of the secondary structures may provide a clear picture for species identification. Point mutations occur continuously and at random through the prokaryotic genome at every multiplication phase. Although point mutations occur in both the translated and untranslated regions at the same rate, incidence of some nucleotide substitutions, observed in the controlling regions of prokaryotic genomes, are biased by the selection of lethal mutation. These lethal mutations are not obvious in critical regions of the prokaryotic $r n p B$ gene that is responsible for processing the 5' end of tRNA by cleaving a precursor and leading to tRNA maturation. The secondary structure differences delineated the differences between the two species more clearly than the nucleotide sequence alignments, which only showed a small number of differences and some of these are common to both species. Therefore, comparison of the secondary structures may be more meaningful than the phylogenetic analysis of the $\operatorname{rnp} B$ nucleotide sequences.

There have only been two hemoplasma species, $M$. suis and E. parvum, recognized in swine [18], that have been distinguished by morphology and pathogenecity [17, 19]. In the present study, we demonstrated two genetic clusters among swine hemoplasmas. One of them was classified as $M$. suis according to nucleotide sequence homology of the 16S rRNA gene. The nucleotide sequence of the 16S rRNA gene of $M$. suis was first determined on the Illinois strain which had been maintained by serial passage in pigs, and deposited in DNA databases under the accession number U88565 [15]. However, E. parvum has not been maintained in vivo so far, and this has long hampered to identification of this particular species. The accumulated data in the present study suggested the cluster B strains, distinct from M. suis by phylogenic analysis, were thus a new hemoplasma species or most likely to be E. parvum, which is the only hemoplasma species remaining in the genus Eperythrozoon [13]. All the other recognized species in this genus have already been transferred to the genus Mycoplasma [11, 12]. Our results indicated that the novel cluster was genetically close to the Mycoplasma species, suggesting that this taxon should be included in the genus Mycoplasma. In conclusion, the present study reports the existence of two genetically distinct clusters among swine hemoplasmas, representing $M$. suis and a provisional M. parvum.

\section{REFERENCES}

1. Barnett, S. F. 1963. Eperythrozoon parvum in pig in Kenya. Bull. Epiz. Dis. Afr. 11: 185-195.

2. Drancourt, M. and Raoult, D. 2005. Sequence-based identification of new bacteria: a proposition for creation of an orphan bacterium repository. J. Clin. Microbiol. 43: 4311-4315.

3. Freier, S. M., Kierzek, R., Jaeger, J. A., Sugimoto, M., Caruthers, M. H., Nielson, T. and Turner, D. H. 1986. Improved freeenergy parameters for predictions of RNA duplex stability. Proc. Natl. Acad. Sci. U.S.A. 83: 9373-9377.

4. Harasawa, R., Mizusawa, H., Fujii, M., Yamamoto, J., Mukai, H., Uemori, T., Asada, K. and Kato, I. 2005. Rapid detection and differentiation of the major mycoplasma contaminants in cell cultures using real-time PCR with SYBR Green I and melting curve analysis. Microbiol. Immunol. 49: 859-863.

5. Henderson J. P., O'Hagan, J., Hawe, S. M. and Pratt, M. C. 1997. Anaemia and low viability in piglets infected with Eperythrozoon suis. Vet. Rec. 140: 144-146.

6. Henry, S. C. 1979. Clinical observations on eperythrozoonosis. J. Am. Vet. Med. Assoc. 174: 601-603.

7. Kimura, M. 1980. A simple method for estimating evolutionary rates of base substitutions through comparative studies of nucleotide sequences. J. Mol. Evol. 16: 111-120.

8. Krasilnikov, A. S., Yang, X., Pan, T. and Mondragon, A. 2003. Crystal structure of the specificity domain of ribonuclease $\mathrm{P}$. Nature 421: 760-764.

9. Massire, C., Jaeger, L. and Westhof, E. 1997. Phylogenetic evidence for a new tertiary interaction in bacterial RNase P RNAs. RNA 3: 553-556.

10. Messick, J. B. 2004. Hemotrophic mycoplasmas (hemoplasmas): a review and new insights into pathogenic potential. Vet. Clin. Pathol. 33: 2-13.

11. Neimark, H., Johansson, K. E., Rikihisa, Y. and Tully, J. G. 2001. Proposal to transfer some members of the genera Haemobartonella and Eperythrozoon to the genus Mycoplasma with the descriptions of 'Candidatus Mycoplasma haemofelis', 'Candidatus Mycoplasma haemomuris', 'Candidatus Mycoplasma haemosuis' and 'Candidatus Mycoplasma wenyonii'. Int. J. Syst. Evol. Microbiol. 51: 891-899.

12. Neimark, H., Johansson, K. E., Rikihisa, Y. and Tully, J. G. 2002. Revision of haemotrophic mycoplasma species names. Int. J. Syst. Evol. Microbiol. 52: 683.

13. Neimark, H., Peters, W., Robinson, B. L. and Stewart, L. B. 2005. Phylogenetic analysis and description of Eperythrozoon coccoides, proposal to transfer to the genus Mycoplasma as Mycoplasma coccoides comb. Nov. and request for an opinion. Int. J. Syst. Evol. Microbiol. 55: 1385-1391.

14. Peters, I. R., Helps, C. R., McAuliffe, Neimark, H., Lapin, M. R., Gruffydd-Jones, T. J., Day, M. J., Hoelzle, L. E., Willi, B., Meli, M., Hofmann-Lehmann, R. and Tasker, S. 2008. RNase P RNA gene $(r n p B)$ phylogeny of hemoplasmas and other Mycoplasma species. J. Clin. Microbiol. 46: 1873-1877.

15. Rikihisa, Y., Kawahara, M., Wen, B., Kociba, G., Fuerst, P., Kawamori, F., Suto, C., Shibata, S. and Futohashi, M. 1997. Western immunoblot analysis of Haemobartonella muris, and comparson of 16S rRNA gene sequences of H. muris, H. felis, and Eperythrozoon suis. J. Clin. Microbiol. 35: 823-829.

16. Saitou, N. and Nei, M. 1987. The neighbor-joining method: a new method for reconstructing phylogenetic trees. Mol. Biol. Evol. 4: 406-425.

17. Seamer, J. 1960. Studies with Eperythrozoon parvum Splitter, 1950. Parasitology 50: 67-80.

18. Splitter, E. J. 1950. Eperythrozoon suis n. sp. and Eperythrozoon parvum n. sp., two new blood parasites of swine. Science 111: 513-514.

19. Splitter, E. J. 1953. Eperythrozoon parvum, a filtrable blood parasite of swine. Nature 172: 40.

20. Täpp, J., Thollesson, M. and Hermann, B. 2003. Phylogenetic relationships and genotyping of the genus Streptococcus by sequence determination of the RNase P RNA gene, rnpB. Int. J. Syst. Evol. Microbiol. 53: 1861-1871.

21. Thompson, J. D., Higgins, D. G. and Gibson, T. J. 1994. CLUSTAL W: improving the sensitivity of progressive multiple sequence alignment through sequence weighting, positionspecific gap penalties and weight matrix choice. Nucleic Acids 
Res. 22: 4673-4680.

22. Watanabe, Y., Fujihara, M., Obara, H., Matsubara, K., Yamauchi, K. and Harasawa, R. 2010. Novel hemoplasma species detected in free-ranging Sika deer (Cervus nippon). J. Vet. Med. Sci. 72: 1527-1530.

23. Yao, C., Liang, A., Yuan, C., Xia, J., Bo, L., Zheng, W., Yang, Z. and Hua, X. 2010. Overexpresssion of complement receptor type 1 (CR1, CD35) on erythrocytes in patients with hemoplasma infection. Microbiol. Immunol. 54: 460-465.

24. Yuan, C. L., Liang, A. B., Yao, C. B., Yang, Z. B., Zhu, J. G., Cui, L., Yu, F., Zhu, N. Y., Yang, X. W. and Hua, X. G. 2009. Prevalence of Mycoplasma suis (Eperythrozoon suis) infection in swine and swine-farm workers in Shanghai, China. Am. J. Vet. Res. 70: 890-894.

25. Zachary, J. F. and Basgall, E. J. 1985. Erythrocyte membrane alterations associated with the attachment and replication of Eperythrozoon suis: a light and electron microscopic study. Vet. Pathol. 22: 164-170.

26. Zinn, G. M., Jesse, G. W. and Dobson, A. W. 1983. Effect of eperythrozoonosis on sow productivity. J. Am. Vet. Med. Assoc. 182: 369-371.

27. Zuker, M. and Stiegler, P. 1981. Optimal computer folding of large RNA sequences using thermodynamics and auxiliary. Nucleic Acids Res. 9: 133-148. 